\title{
Effect of Designed Nursing Guidelines on Outcomes of Patients Undergoing Tympanoplasty
}

\author{
Zeinab Sameir Ibrahime ${ }^{1}$, Hussein Fareid Weshahy ${ }^{2}$, Hala Mohammed Ghanem ${ }^{3} \&$ Esmat Sayed Abdelmaged $^{4}$ \\ ${ }^{1 .}$ Nursing specialist in Assiut University Hospital, Egypt. \\ ${ }^{2 .}$ Professor of Otolaryngology, Faculty of Medicine, Assiut University, Egypt. \\ 3. Assistant Professor of Medical -Surgical Nursing. Faculty of Nursing, Assiut University, Egypt. \\ 4. Assistant Professor of Medical- Surgical Nursing, Faculty of Nursing, Assiut University, Egypt
}

\begin{abstract}
Tympanoplasty is a surgical technique to repair a defect in the tympanic membrane with the placement of a graft. Aim: To evaluate the effect of the designed nursing guidelines on outcomes of patients undergoing tympanoplasty. Research design: Quasi-experimental research design. Setting: Otolaryngology department and Outpatient Clinics at Assiut University Hospital. Patients: Sixty adult patients undergoing tympanoplasty were distributed into two equal groups (study and control) 30 patients for each. Tools: Tool I: Patient Questionnaires Sheet, Tool II: Hearing Handicap Inventory for Adults (HHIA) Scale. Results: Study group patients showed highly statistically significant improvement in their level of knowledge as well as social and emotional responses of hearing handicap than the control group $(\mathrm{P}<0.01)$. Conclusion: the designed nursing guidelines for patients undergoing tympanoplasty had a significant effects on improvement of patients' knowledge as well as social and emotional responses of hearing handicap. Recommendations: Teaching materials about pre and postoperative and home instructions should be available in Otolaryngology for patients undergoing tympanoplasty.
\end{abstract}

\section{Keywords: Nursing Guidelines, outcomes \& tympanoplasty.}

\section{Introduction}

Tympanic membrane perforation is a hole or tears in the thin tissue that separates ear canal from middle ear. A ruptured eardrum can result in hearing loss. It can also make middle ear vulnerable to infections. A ruptured eardrum usually heals within a few weeks without management. But sometimes it requires a patch or surgical repair to heal (Stomackin et al., 2019).

Tympanoplasty is a surgical technique to repair a defect in the tympanic membrane with the placement of a graft, either medial or lateral to the tympanic membrane annulus. The goal of this surgical procedure is not only to close the perforation but also to improve hearing. Various techniques have been developed and refined, and a number of grafting materials are accessible (El-Feky et al., 2019).

In the literature, tympanic membrane closure success rates range from 35 to 98 percent, but are typically higher than 80 percent and are dependent on the size and position of the perforation, surgical procedure, and overall middle ear health. A proper and thorough preoperative evaluation, as well as the careful construction of an efficient surgical plan, will improve outcomes (Sajid et al., 2017).

Nurses play an important role for patients undergoing tympanoplasty because those patients are needed for special nursing care and education to improve the patients`state, reducing or preventing postoperative complications, and improve patients' general condition (Sonya, 2018).

Nurses should assess the patients hearing or verify documentation of preoperative hearing valuation. These data are important in evaluating the results of the surgical technique. Agree on a means of communication to be used after surgery. Nurses should explain that blowing of the nose, coughing, and sneezing are restricted to prevent pressure changes in the middle ear and potential disruption of the surgical location. If the patient needs to cough or sneeze, leaving the mouth open minimizes pressure changes in the middle ear. Providing teaching and the opportunity to practice before surgery promotes the patient's cooperation in the postoperative period (Keseroğlu et al., 2019).

Tympanic membrane perforations can cause a conductive hearing loss. Social, emotional and environmental aspects of quality of life (QoL) are affected with hearing loss status; treatment helps a lot to improve these aspects Wang et al. (2019). Also, nursing guidelines which include all the needed instructions that helped in healing process may help in improving social and emotional responses of hearing handicap.

\section{Significance of the study}

Over $5 \%$ of the world's population or 466 million people have disabling hearing loss. It is estimated that by 2050 over 900 million people or one in every 
ten people will have disabling hearing loss (WHO, 2017). According to statistical record of Assiut University Hospital, the number of patients undergoing tympanoplasty was approximately (200) in 2019. Also, from the researcher's experience as a nursing supervisor in Otolaryngology department, patients undergoing tympanoplasty don't receive enough knowledge regarding the surgery, so this study will be conducted to provide nursing guidelines for those patients to improve their knowledge and social and emotional responses of hearing handicap.

\section{Aim of the study}

The aim of this study was to evaluate the effect of the designed nursing guidelines on outcomes (knowledge and social and emotional responses of hearing handicap) of patients undergoing tympanoplasty.

\section{Research Hypotheses}

To fulfill the aim of the study, the following research hypotheses were formulated.

- Mean knowledge score of the study group will be higher than the control group.

- Social and emotional responses of hearing handicap will improve among the study group than among the control group.

\section{Operational definitions:}

Patients` outcomes: Patients` knowledge as well as social and emotional responses of hearing handicap.

\section{Patients and methods:}

Study design:

Quasi-experimental research design was utilized in this study.

\section{Study variables:}

The independent variable was the designed nursing guidelines, while the dependent variables were patients' knowledge and hearing handicap inventory for adult (HHIA).

\section{Sitting:}

This study was conducted in the Otolaryngology department and Outpatient Clinics at Assiut University Hospital.

\section{Sample:}

A convenience sample of 60 adult patients with tympanic membrane perforation, from both sexes, and their age ranged from (18-65) year. The patients were admitted in Otolaryngology department for tympanoplasty surgery. Those 60 patients were equally divided on random basis into study and control groups 30 patients for each. Study group received the designed nursing guidelines, while the control group received the routine hospital care.

\section{Exclusion criteria:}

1. Underlying diseases such as poor immune system as cancer.
2. Definite diagnosis of cholesteatoma and ossicular erosion.

3. Presence of a Sensorineural Hearing Loss (SNHL).

Tools:

Two tools were used in this study.

Tool I: Patient Questionnaire Sheet: It was designed by researcher after reviewing the current national and international literatures, it consisted of two parts:

Part (1): Demographic data of the patients: Age, gender, and level of education, marital status and occupation.

Part (2): Patients' knowledge about tympanic membrane perforation and tympanoplasty: definition, causes, signs and symptoms, complications, management, pre and postoperative teaching, and home instructions.

Scoring system:

The total numbers of questions were 24 list questions, 4 grades awarded for the correct answer, 2 grades for the incomplete answer, and zero for the incorrect (don't know). Also, 9 true and false questions, two grades for the correct answer and zero for the incorrect one. The total grade was 114 .The total knowledge score was determined as follow:

$$
\begin{aligned}
& \text { - Poor }<50 \% \\
& \text { - Fair } 50 \% \text { - } 70 \% \\
& \text { - Good } \geq 70 \%
\end{aligned}
$$

Tool II: Hearing Handicap Inventory for Adults (HHIA) Scale:

It was developed by Weinstein et al. (1991). It consists of 25 questions broken down into subscales: social (12 questions, which measure the effects of hearing loss in different social situations) and emotional (13 questions, which estimate the behavior and emotional responses of the individual in relation to this hearing loss). Each question has three responses; Yes $=4$, Sometimes $=2$, and No = zero It was adopted by the researcher to assess social and emotional responses of hearing handicap as a result of tympanic membrane perforation.

\section{Scoring system:}

Scores ranged from 0 (no handicap) to 100 (total handicap):

$0-16 \%=$ no handicap

$18-42 \%=$ mild to moderate handicap

Above $44 \%=$ Significant handicap.

The designed nursing guidelines for patients undergoing tympanoplasty:

This was developed by the researcher based on reviewing current national and international literatures (Cunha and Conrad, 2019 \& and Miyamoto, 2019) it included:

- Brief anatomy of the ear.

- Definition of tympanic membrane perforation. 
- Causes or risk factors for tympanic membrane perforation.

- Signs and symptoms of tympanic membrane perforation.

- Treatment of tympanic membrane perforation.

- Brief description of the surgery.

- Post tympanoplasty complications.

- Nursing guidelines for patients before and after tympanoplasty and home instructions that may help in healing process which can have appositive effect on improving hearing HHIA score:

- Medications

- Dressing.

- Diet.

- Physical activity.

- How to prevent infection of the ear.

- Signs and symptoms that the patient must return immediately to the hospital.

- Follow-up appointments after discharge from the hospital.

- Experts in the fields of Nursing and Otolaryngology checked the content for clarity and applicability and corrections were carried out accordingly.

\section{Methods \\ Ethical considerations:}

1. Research proposal was approved from Ethical Committee in the Faculty of nursing.

2. There was no risk for study subject during application of research.

3. The study followed common ethical principles in clinical research.

4. Oral consent was obtained from patient's that participated in study, after explaining the nature and purpose the study.

5. Confidentiality and anonymity were assured.

6. Patients had the right to refuse to participate and or withdraw from the study without any rational any time.

7. Patient's privacy was considered during collection of data.

\section{Procedure}

The study was carried out on three phases:

\section{Preparatory phase:}

This phase stared by a review of current and past, local and international related literature as textbooks, articles, journals, periodicals, and magazines, study tools were formulated, and this phase ended by contents validity and pilot study.

\section{Content validity and reliability:}

It was checked by five expertise (3 from medical surgical nursing staff and 2 from Otolaryngology staff) who reviewed the tools for clarity, relevance and applicability; minor modifications were required. Test reliability of the tools was confirmed by Cranach's alpha = 0.89 for (tool I part 2) and 0.97 for (tool II).

Pilot study:

It was carried on $10 \%$ of the sample (6 patients) to test the feasibility and practicability of the study tools. Also, it provides an estimate of time needed to fill out the tools. Those patients were included in the main study as no modifications were done in the tools.

Implementation phase:

An official letter was issued to the head of the Otolaryngology department to collect the necessary data. The researcher met nursing supervisors and otolaryngology surgeons' specialists for explaining the purpose of the study to gain their cooperation.

At initial interview during the preoperative period the researcher introduced herself to initiate line of communication. The researcher divided the patients randomly into both study and control groups and interviewed with each patient individually and explained the nature and purpose of the study. Baseline data were established using (tool I \& II).

The control group patients were exposed to the routine hospital care (included; take complete history, physical examination, diagnostic test, informed consent and taking prescribed medications). The study group patients exposed to the routine hospital care in addition to the designed nursing guidelines by the researcher.

Each patient was met for one session which took about 30 - 45 minutes in the Otolaryngology department during morning and afternoon shift. At the end of the session the researcher discussed with the patient each point of guidelines to ensure appropriate understanding. During the session each patient was given a written copy of the booklet in a clear Arabic language.

The researcher ensure commitment of the study group patients to implement the nursing guidelines through daily visiting during hospitalization and weekly by telephone after discharge. The nursing guidelines were carried out throughout a period of 2 months for the study group. Data were collected through the period from the beginning of April 2019 to the end of February 2020.

Evaluation phase:

In this phase, both study and control group patients were reassessed before hospital discharge in the Otolaryngology department using (tool I part 2) and also after 2 months in the outpatient clinics using (tools I part $2 \&$ tool II) to assess the effect of 
nursing guidelines on patients' outcomes. The session took about 30 minutes.

\section{Statistical design:}

Collected data was analyzed and tabulated .The researcher used an appropriate statistical method and tests for analysis of the result. The statistical package for (SPSS) version (23) was used to analyze data.
Descriptive statistics was used for the quantitative data. It included frequencies, percentages, and mean \pm SD. Pearson Correlation (Correlation is significant at the 0.05 level). The level of significance for this study was set at $(p<0.05)$ to detect any indication of differences found in the data available.

\section{Results:}

Table (1): Frequency distribution of the studied sample (control and study groups) regarding their demographic characteristics.

\begin{tabular}{|c|c|c|c|c|c|}
\hline \multirow{2}{*}{$\begin{array}{c}\text { Demographic } \\
\text { characteristics }\end{array}$} & \multicolumn{2}{|c|}{$\begin{array}{c}\text { Study } \\
(\mathbf{n} .=30)\end{array}$} & \multicolumn{2}{|c|}{$\begin{array}{l}\text { Control } \\
(\mathbf{n} .=30)\end{array}$} & \multirow{2}{*}{ P. value } \\
\hline & $\overline{1}$ & $\%$ & N. & $\%$ & \\
\hline $\begin{array}{c}\text { Age } \\
18<40 \text { years }\end{array}$ & 25 & 83.3 & 25 & 83.3 & \multirow{2}{*}{$0.635^{\mathrm{NS}}$} \\
\hline $40>60$ years & & 16.7 & 5 & 16.7 & \\
\hline Mean \pm SD & \multicolumn{4}{|c|}{$29 \pm 9.6$} & \\
\hline $\begin{array}{l}\text { Sex } \\
\text { Male }\end{array}$ & 13 & 43.3 & 13 & 43.3 & \multirow{2}{*}{$0.603^{\mathrm{NS}}$} \\
\hline Female & 17 & 56.7 & 17 & 56.7 & \\
\hline $\begin{array}{c}\text { Marital status } \\
\text { Single }\end{array}$ & 17 & 56.7 & 14 & 66.7 & \multirow{3}{*}{$0.453^{\mathrm{NS}}$} \\
\hline Married & 12 & 40.0 & 15 & 50.0 & \\
\hline Widow & 1 & 3.3 & 1 & 3.3 & \\
\hline $\begin{array}{c}\text { Level of education } \\
\text { High educated }\end{array}$ & 1 & 3.3 & 0 & 0.0 & \multirow{4}{*}{$0.415^{\mathrm{NS}}$} \\
\hline Secondary & 12 & 40.0 & 8 & 26.6 & \\
\hline Read and write & 6 & 20.0 & 12 & 40.0 & \\
\hline Not educate & 11 & 36.7 & 10 & 33.3 & \\
\hline \multicolumn{6}{|l|}{ Occupation } \\
\hline Employee & 4 & 13.3 & 2 & 6.7 & \multirow{4}{*}{$0.712^{\mathrm{NS}}$} \\
\hline Farmer & 4 & 13.3 & 5 & 16.7 & \\
\hline House wife & 9 & 30.0 & 12 & 40.0 & \\
\hline Not work & 13 & 43.3 & 11 & 37.7 & \\
\hline
\end{tabular}

Independent sample T-test

NS: not significant. $p>.05$

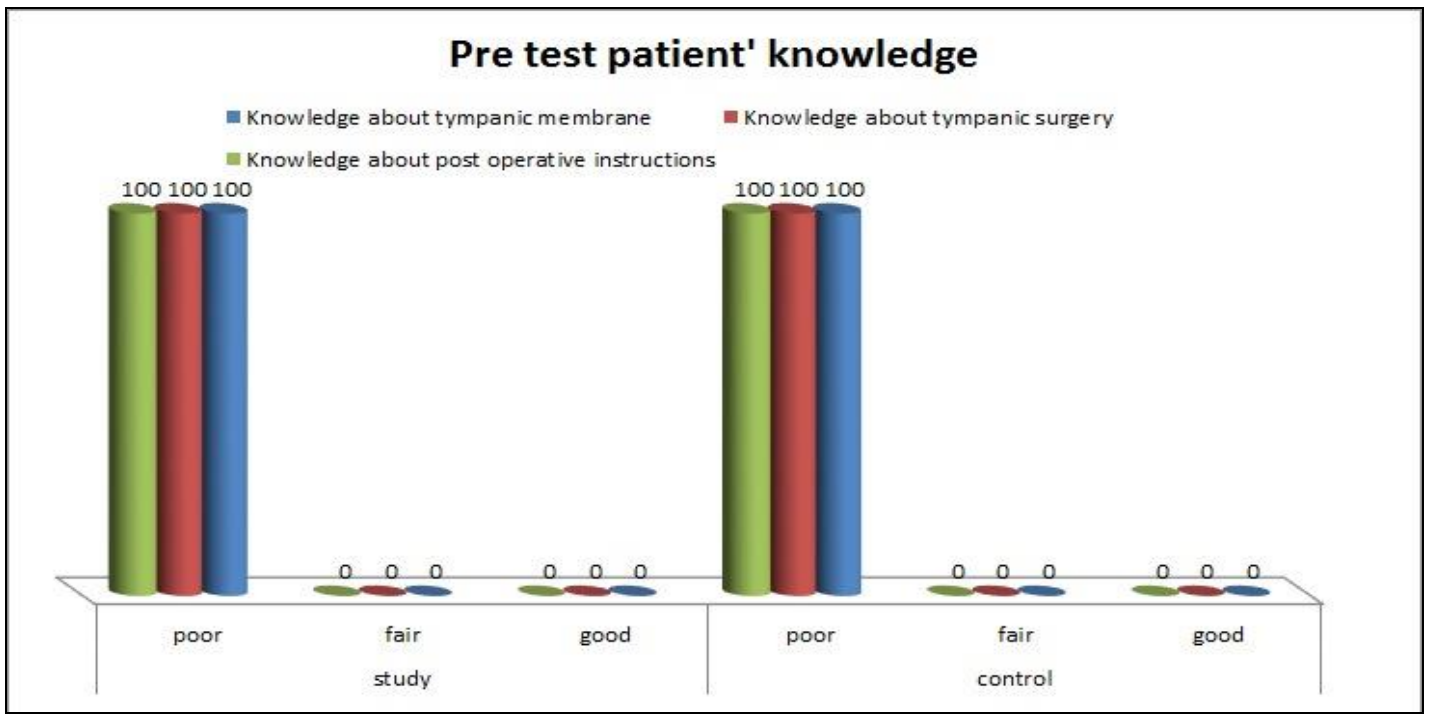

Fig (1): Comparison between study and control groups regarding their level of knowledge in pre-test. 
Table (2): Comparison between study and control groups regarding their level knowledge post and follow up (after 2 months) the application of the designed nursing guidelines.

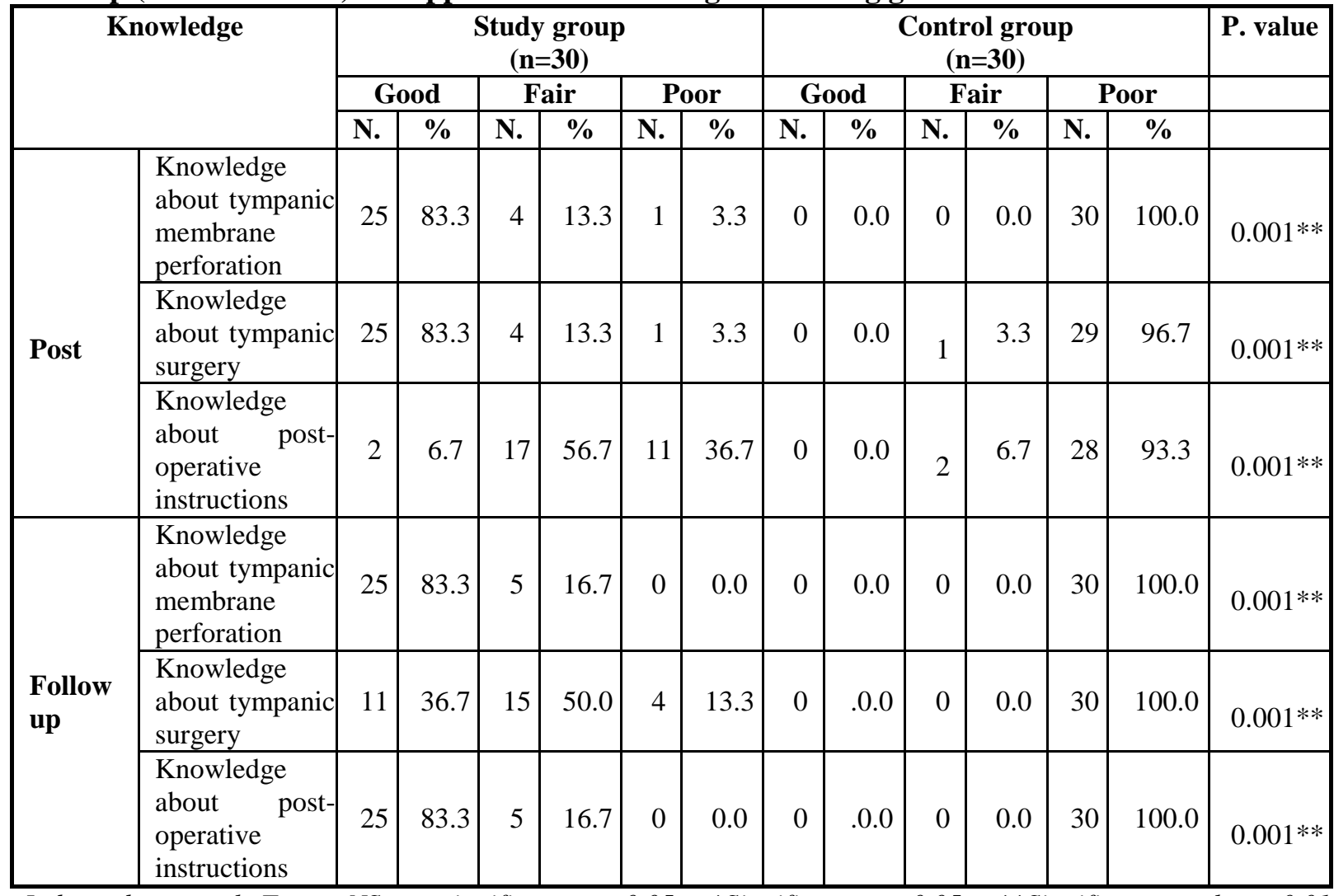

Independent sample T-test NS: not significant p. $<0.05, \quad{ }^{*}$ Significant $p .<0.05, \quad{ }^{*}$ Significant $p$. value $<0.01$

Table (3): The mean knowledge scores of study and control groups about tympanoplasty.

\begin{tabular}{|l|c|c|c|}
\hline \multicolumn{1}{|c|}{ knowledge scores } & $\begin{array}{c}\text { Study group } \\
(\mathbf{n} .=\mathbf{3 0})\end{array}$ & $\begin{array}{c}\text { Control group } \\
(\mathbf{n} .=\mathbf{3 0})\end{array}$ & \multirow{2}{*}{. value } \\
\hline & Mean \pm SD & Mean \pm SD & \\
\hline Pre- Test & $10.6 \pm 5.3$ & $10.2 \pm 5.4$ & $\mathbf{0 . 1 3 7 ~ N S}$ \\
\hline Post-Test & $82.6 \pm 13.9$ & $16.9 \pm 9.7$ & $\mathbf{0 . 0 0 1} * *$ \\
\hline Follow up & $63.13 \pm 12.1$ & $18.6 \pm 6.4$ & $\mathbf{0 . 0 0 1} * *$ \\
\hline
\end{tabular}

Table (4): Comparison between study and control groups regarding hearing handicap inventory scores pre and follow up ( 2 months) the application of the designed nursing guidelines.

\begin{tabular}{|c|c|c|c|c|c|c|c|c|c|c|c|c|c|}
\hline \multirow{3}{*}{\begin{tabular}{l}
\multicolumn{1}{c}{ Hearing } \\
Handicap \\
Inventory for \\
Adults (HHIA) \\
HHIA \\
Emotional
\end{tabular}} & \multicolumn{6}{|c|}{$\begin{array}{l}\text { Study } \\
(n=30)\end{array}$} & \multicolumn{6}{|c|}{$\begin{array}{c}\text { Control } \\
(\mathbf{n}=\mathbf{3 0})\end{array}$} & $\begin{array}{c}\text { P. } \\
\text { Value }\end{array}$ \\
\hline & \multicolumn{2}{|c|}{$\begin{array}{c}\text { No } \\
\text { handicap }\end{array}$} & \multicolumn{2}{|c|}{$\begin{array}{l}\text { Moderate } \\
\text { Handicap }\end{array}$} & \multicolumn{2}{|c|}{$\begin{array}{c}\text { Significant } \\
\text { handicap }\end{array}$} & \multicolumn{2}{|c|}{$\begin{array}{c}\text { No } \\
\text { handicap }\end{array}$} & \multicolumn{2}{|c|}{$\begin{array}{l}\text { Moderate } \\
\text { Handicap }\end{array}$} & \multicolumn{2}{|c|}{$\begin{array}{l}\text { Significant } \\
\text { handicap }\end{array}$} & \\
\hline & N. & $\%$ & N. & $\%$ & N. & $\%$ & N. & $\%$ & N. & $\%$ & N. & $\%$ & \\
\hline Pre & 18 & 60 & 4 & 13.3 & 8 & 26.7 & 20 & 66.7 & 5 & 16.7 & 5 & 16.7 & \\
\hline Mean \pm SD & \multicolumn{6}{|c|}{$12.2 \pm 5.1$} & \multicolumn{6}{|c|}{$14.02 \pm 6.8$} & $0.656 \mathrm{~ns}$ \\
\hline Follow up & 29 & 96.7 & 1 & 3.3 & 0 & 0.0 & 21 & 70 & 0 & 0.0 & 9 & 30 & \\
\hline Mean \pm SD & \multicolumn{6}{|c|}{$21.08 \pm 6.08$} & \multicolumn{6}{|c|}{$15.07 \pm 4.4$} & $0.001 * *$ \\
\hline p. value & \multicolumn{6}{|c|}{ 0.001** } & \multicolumn{6}{|c|}{$0.541^{\mathrm{ns}}$} & $0.001 * *$ \\
\hline
\end{tabular}




\begin{tabular}{|c|c|c|c|c|c|c|c|c|c|c|c|c|c|}
\hline \multirow{3}{*}{\begin{tabular}{|l|c|}
\multicolumn{1}{|c}{ Hearing } \\
Handicap \\
Inventory for \\
Adults (HHIA) \\
HHIA \\
Emotional
\end{tabular}} & \multicolumn{6}{|c|}{$\begin{array}{l}\text { Study } \\
(\mathrm{n}=30)\end{array}$} & \multicolumn{6}{|c|}{$\begin{array}{c}\text { Control } \\
(\mathbf{n}=30)\end{array}$} & $\begin{array}{c}\text { P. } \\
\text { Value }\end{array}$ \\
\hline & \multicolumn{2}{|c|}{$\begin{array}{c}\text { No } \\
\text { handicap }\end{array}$} & \multicolumn{2}{|c|}{$\begin{array}{l}\text { Moderate } \\
\text { Handicap }\end{array}$} & \multicolumn{2}{|c|}{$\begin{array}{c}\text { Significant } \\
\text { handicap }\end{array}$} & \multicolumn{2}{|c|}{$\begin{array}{c}\text { No } \\
\text { handicap }\end{array}$} & \multicolumn{2}{|c|}{\begin{tabular}{|l|} 
Moderate \\
Handicap \\
\end{tabular}} & \multicolumn{2}{|c|}{$\begin{array}{l}\text { Significant } \\
\text { handicap }\end{array}$} & \\
\hline & N. & $\%$ & N. & $\%$ & $\mathbf{N}$. & $\%$ & N. & $\%$ & N. & $\%$ & N. & $\%$ & \\
\hline \multicolumn{14}{|l|}{ HHIA - Social } \\
\hline Pre & 17 & 56.7 & 10 & 33.3 & 3 & 10 & 18 & 60 & 4 & 13.3 & 8 & 26.7 & $0.0738 n$ \\
\hline Mean \pm SD & \multicolumn{6}{|c|}{$11.6 \pm 6.53$} & \multicolumn{6}{|c|}{$12.2 \pm 5.1$} & \\
\hline Follow up & 29 & 96.7 & 1 & 3.3 & 0 & 0.0 & 20 & 66.7 & 5 & 16.7 & 5 & 16.7 & \\
\hline Mean \pm SD & \multicolumn{6}{|c|}{$21.08 \pm 6.08$} & \multicolumn{6}{|c|}{$14.02 \pm 6.8$} & $0.001 * *$ \\
\hline p. value & \multicolumn{6}{|c|}{$0.001 * *$} & \multicolumn{6}{|c|}{$0.172^{\mathrm{Ns}}$} & $0.001 * *$ \\
\hline \multicolumn{14}{|l|}{ HHIA total score } \\
\hline Pre & 20 & 66.7 & 5 & 16.7 & 5 & 16.7 & 18 & 60 & 4 & 13.3 & 8 & 26.7 & \\
\hline Mean \pm SD & \multicolumn{6}{|c|}{$14.02 \pm 6.8$} & \multicolumn{6}{|c|}{$12.2 \pm 5.1$} & $0.656 \mathrm{~ns}$ \\
\hline Follow up & 29 & 96.7 & 1 & 3.3 & 0 & 0.0 & 25 & 83.3 & 1 & 3.3 & 4 & 13.3 & $0.001 * *$ \\
\hline Mean \pm SD & \multicolumn{6}{|c|}{$21.08 \pm 6.08$} & \multicolumn{6}{|c|}{$17.02 \pm 4.02$} & \\
\hline p. value & \multicolumn{6}{|c|}{ 0.001** } & \multicolumn{6}{|c|}{$0.409^{\mathrm{Ns}}$} & 0.001*** \\
\hline
\end{tabular}

Independent sample T-test $\quad$ NS: not significant p. $>0.05 \quad{ }^{*}$ Significant t $p .<0.01$

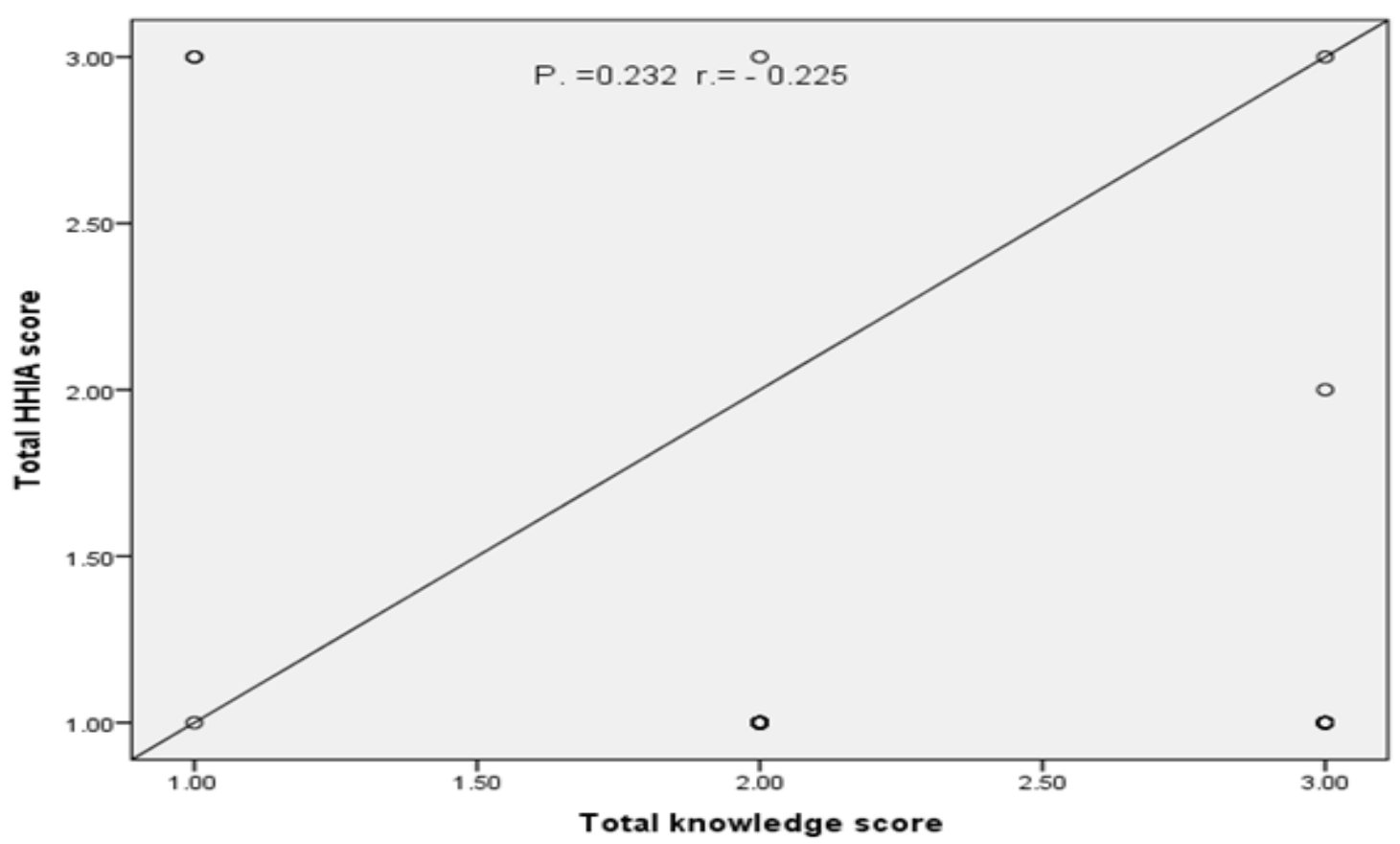

Figure (2): Correlation between total knowledge scores and total HHIA score of study group during the follow up period ( 2 months) after application of the designed nursing guidelines

Table (1): Shows that the mean age of both study and control group was $(29 \pm 9.6)$. The highest percentage of them was female (56.7\%) and single (56.7 and $66.7 \%$ ) respectively). $40 \%$ of the study group was secondary school but the control group was read and write, regarding their occupation $43.3 \%$ of the study group was house wife and $40 \%$ of the control group was not work. No statistical significance difference was found between both groups regarding the demographic data.

Figure (1): Shows that no statistically significant difference was found between the study and the control group regarding their knowledge about tympanic membrane perforation, tympanic surgery and home instructions in pre-test. 
Table (2): Significant statistically differences were found between the study and control group regarding their knowledge about tympanic membrane perforation, tympanic surgery and home instructions in post-test and follow up period $(\mathrm{P}<0.01)$.

Table (3): Reveals that no statistically significant difference was found between the study and the control groups in pre- test as base line data. While, in post -test and during the follow up period after application of the nursing guidelines, study group patient showed highly statistically significant improvement in their level of knowledge than the control group $(\mathrm{P}<0.01)$.

Table (4): Shows no statistically significant differences were found between the study and the control groups regarding handicap inventory (social HHIA, emotional HHIA, and total HHIA) scores in pre-test. While, during the follow up period after application the designed nursing guidelines, statistically significant improvement were found among the study and the control groups (p. < 0.01). However, the improvement was more obvious among the study group than among the control group ones.

Figure (2): Shows that no statistical significant correlation was found among the study and control groups regarding total knowledge and total HHIA scores during the follow up period (2month) after application the designed nursing guidelines.

\section{Discussion:}

Enhanced recovery after surgery is a series of multidisciplinary initiatives adopted in the perioperative phase to improve the perioperative patient experience and outcomes and to reduce psychological and physical stress reactions. Many organizations, also have issued guidelines for tympanoplasty (Mahairas et al., 2020).

Regarding demographic data the present study showed that the mean age of both study and control group was (29 \pm 9.6$)$ the highest percentage of the studied patients were female which may be due to woman with hearing problem less likely to use hearing aids than men. Also, about two fifth of them were house wives not work, secondary school, and read and write.

The current results matched with Çayir \& Kayabaşi (2019) who documented that the main age of patients undergoing tympanoplasty was between 20 to 40 years old. Also, the study finding was in the line with Weiss et al. (2017) who reported that, more females than males have hearing problem and undergoing hearing surgery they added that this is partly explicable by the longer life span of women and therefore over-representation in the age groups where hearing is most common.
Similarly, a study conducted by Spanoudakis et al. (2017) regarding prevention and management of hearing problem among adults reported that the majority of patients were females married and house wives. Also $\mathbf{L i}$ et al. (2020) found that large percentage of patients undergoing tempanoplasty was not work. While, Kaya et al. (2018) found the opposite results that the majority of sample were employees.

Regarding patients' knowledge about tympanoplasty the current study showed that both study and control group patients didn't have enough knowledge about tympanoplasty in pretest, which mean that patients didn't receive enough knowledge from the health care team, while, in post -test and during the follow up period after application the designed nursing guidelines, study group patient showed highly statistically significant improvement in their level of knowledge than the control group, from the researcher point of view this may be due to containment of the nursing guidelines with all needed knowledge about tympanic membrane perforation, tympanic surgery and home instructions. Also, continuous follow up of the study group by the researcher up to 2 month to ensure retain of information.

In this regard Sheikh (2019) emphasized that patient teaching is important because the patient has the right to know and to be informed about diagnosis, prognosis of illness, treatment options, risks associated with treatments. A well designed, comprehensive teaching plan that fits patients' unique learning needs improves quality, reduces health care cost and allows them to become more independent. Fu et al. (2020) added that education is the key to successful treatment of the disease, and the nurse plays a major role as patient educator. Patients and their families need accurate information about the disease and about the strategies to minimize its impact.

The current study results agreed with Collinson (2020) who carried out a study to investigate the implementation of structured teaching guidelines about hearing loss and management, he found that before application the teaching guidelines all the studied sample were having poor knowledge, however after application the guidelines they found significant improve in knowledge level. This improvement emphasizes the fact that, most patients have a strong desire to learn more knowledge about their conditions and also showed the effect of the guidelines. Also, Rana et al. (2020) found that there was highly significant difference between pre knowledge and post knowledge regarding tympanic surgery in their comparative study for cartilage tympanoplasty. 
As regard to hearing handicap inventory for adults (HHIA), the present study revealed that about one third of both study and control group patients had moderate and significant handicap in pre-test, which may be due to the effect of tympanic membrane perforation that can cause hearing loss which affects the patients social and emotional response. However during the follow-up period (2 months) after application the designed nursing guideline both study and control group showed improvement in HHIA scores but it was significantly obvious among the study group than the control group.

From the researcher point of view this may be due to the effect of tympanoplasty which corrected the hearing problem, plus the effect of the nursing guidelines which included all the needed instructions that helped in healing process (e.g. Dressing, how to prevent infection of ear, medication, and the important of follow-up after discharge), in addition to the 2 months follow-up period by the researcher to ensure implementation of the nursing guidelines.

In this regard Son \& Heo (2018) stated that according to the speculative model of temporallyevolving impairment, disability and handicap, individuals choose to pursue amplification because the hearing impairment has begun to interfere with QoL. Specifically, the impairment domain of auditory function/dysfunction appears to increase slowly over time and affect physical, psychological and social domains or dimensions of health status.

Similarly, Lailach et al. (2020) conducted study about middle ear surgery in patients with chronic otitis media, they found several participants with tympanoplasty hearing loss showed significant improvements in both social and emotional aspects after health education guidance, and stated that similar results have been reported in other studies.

Regarding the correlation between total knowledge and total HHIA score of study group after 2 months (follow up) of the application of the designed nursing guidelines. The current study showed no statistical significant correlation was found between total knowledge and total HHIA score.

\section{Conclusion:}

The designed nursing guidelines for patients undergoing tympanoplasty had significant effects on improvement of patients 'knowledge as well as social and emotional responses of hearing handicap.

\section{Recommendations:}

Teaching materials about pre and postoperative and home instructions should be available in otolaryngology department for patients undergoing tympanoplasty as well as further studies on large sample from different geographical area in Egypt to generalize the result.

\section{References:}

- Çayir, S., \& Kayabaşi, S. (2019): Type 1 tympanoplasty in pediatric patients: Comparison of fascia and perichondrium grafts. International Journal of Pediatric Otorhinolaryngology, 121, 95-98.

- Collinson, R. (2020): New Zealand speech language therapists' knowledge of hearing loss and perspectives on collaboration with the audiology profession.67-88.

- Cunha, J \& Conrad, M (2019): "Perforated (Ruputured) Eardrum" www.emedicinehealth.com

- El-Feky, A. E., Abdelmaksod, M. K., Mohamed, S. A., Aldaem, R. A., \& Yousuf, R. (2019). Interlay Technique Tympanoplasty: Surgical Difficulties with Variable Grafts. Zagazig University Medical Journal, 25(4), 539-547.

- Fu, M., Kurnat-Thoma, E., Starkweather, A., Henderson, W., Cashion, A., Williams, J. \& Calzone, K. (2020): Precision health: A nursing perspective. International journal of nursing sciences, 7(1), 5-12.

- Kaya, I., Turhal, G., Ozturk, A., Gode, S., Bilgen, C., \& Kirazli, T. (2018): The effect of endoscopic tympanoplasty on cochlear function. Clinical and experimental otorhinolaryngology, 11(1), 35.

- Keseroğlu, K., Tokgöz, S., Çelik, E., Akın, İ., \& Özdek, A. (2019): A practical method in measurement of perforation size during cartilage tympanoplasty. The European Research Journal.P.P. 1:4.

- Lailach, S., Langanke, T., Zahnert, T., Garthus-Niegel, S., \& Neudert, M. (2020): Impact of depressive disorders on quality of life after middle ear surgery in patients with chronic otitis media. European Archives of Oto-RhinoLaryngology, 1-9.

- Li, R., Wu, N., Zhang, J., Hou, Z., \& Yang, S. (2020): Analysis on the correlation between Eustachian tube function and outcomes of type I tympanoplasty for chronic suppurative otitis media. Acta Oto-Laryngologica, 1-4.

- Mahairas, A., Neff, R., Craker, N., McNulty, B., Shinn, J., \& Bush, M. (2020): Trends in Opioid Usage Following Tympanoplasty and Mastoidectomy. Otology \& Neurotology, 41(8), e1035-e1040.

- Miyamoto, R. (2019): "Traumatic Perforation of the Tympanic Membrane".

www.msdmanuals.com. 
- Rana, A., Sharma, R., Sharma, V., Mehrotra, A., \& Upadhyay, D. (2020): Intraoperative tragal and conchal cartilage thickness: Comparative study for cartilage tympanoplasty. American Journal of Otolaryngology, 41(6), 102690.

- Sajid, T., Shah, MI., Ghani, R., \& Asif, M. (2017): Type I tympanoplasty by under technique-factors affecting outcome. Journal of Ayub Medical College Abbottabad, 29(2), 258261.

- Sheikh, D. (2019): Outcome of Chronic Suppurative Otitis Media Surgery in Two Teaching Hospitals In Kenya.9-52.

- Son, B., \& Heo, S. (2018): Quality of Life Comparison between Suspicion Hearing Impaired and Hearing Aids Users in Elderly. Journal of the Korean Society of Integrative Medicine, 6(3), 141-147.

- Sonya, H.R (2018): Critical Care Nursing, 9 ed., chapter14, Jones and Bartlett, p.389.

- Spanoudakis, G., Katrakazas, P., Koutsouris, D., Kikidis, D., Bibas, A., \& Pontopidan, N. (2017): Public health policy for management of hearing impairments based on big data analytics: EVOTION at Genesis. 17th International Conference on Bioinformatics and Bioengineering (BIBE). 525-530.

- Stomackin, G., Kidd, S., Jung, T., Martin, G., \& Dong, W. (2019): Effects of tympanic membrane perforation on middle ear transmission in gerbil. Hearing research, 373, 48-58.

- Wang, J., Sung, V., Carew, P., Burt, R., Liu, M., Wang, Y., \& Wake, M. (2019): Prevalence of adults hearing loss and secular trends: a systematic review and meta-analysis. Academic pediatrics, 19(5), 504-514.

- Weinstein, B.E., Newman, CW., Jacobson, G.P. \& Hug, GA. (1991): Test-retest reliability of the Hearing Handicap Inventory for Adults, Ear Hear., PP. (355-357).

- Weiss, D., Böcker, A., Koopmann, M., Savvas, E., Borowski, M., \& Rudack, C. (2017): Predictors of hearing recovery in patients with severe sudden sensorineural hearing loss. Journal of Otolaryngology-Head \& Neck Surgery, 46 (1), $1-10$.

- World Health Organization (2017): Deafness and hearing loss. www.who.int/topic. 